\title{
Integrated Fuzzy PROMETHEE and Fuzzy Linear Program for Functions Evaluation in Convergent Products: Case for Digital Products
}

Ermia Aghasi*, Mansour Momeni and Mohammad Ali Shah Hoseini

Faculty of Management, University of Tehran, Iran

\begin{abstract}
Background/objectives: Recently, convergent products are introduced in digital products. Fast assembly and new product development and dynamic product configuration are all considered in convergent product concept. The fast technology development and dynamic customer demands require a more efficient and flexible system for new product development. This paper proposes an integrated decision making model for convergent product evaluation under fuzzy environment.

Methods/statistical analysis: First the fuzzy decision matrix is formed and using fuzzy PROMETHEE the pairwise comparison is performed. Then, by fuzzy linear programming (FLP) the weights of the functions with respect to attributes pairwise matrices are obtained. Finally, the fuzzy output is transformed to crisp one employing fuzzy analytic hierarchy process (FAHP). The contribution are in developing a new fuzzy linear program, integrate it with PROMETHEE and using them in convergent product function evaluation.

Findings: The results are helpful in business plan and road map of businesses for obtaining competitive advantage and profit maximization. Some of the products are considered and customers' views are collected to form a new product converging the requirements asked by customer's altogether. The dynamic customer views make the system responsive to different convergent products.

Application/improvements: The applicability and the validity of the proposed method are evaluated in a case study. The case study is conducted in a pioneering digital online shopping company. The model is a decision aid for managers of the company to promote to a fast automation assembly system being able to provide product functions integrated to deliver customers' desired products.
\end{abstract}

Keywords: Convergent product; fuzzy PROMETHEE; full fuzzy linear program

\section{Introduction and Literature Review}

The paradigms of digital convergence place more emphasis on strategic gravity of convergent products that are formed by adding new functions to an existing base product [1], multiple functions are integrated together in one device to work better rather than they would be delivered separately. Representative examples of this shifting trend are the cases of Apple's iPhone and Microsoft's Xbox. Such convergent products have created new business opportunities for companies to gain or maintain a competitive edge, bringing about immense changes in a wide array of industries [2]. Consequently, design of convergent product concepts (CPCs) has likewise become an integral part of business concerns [3]. This is of particular importance in the recent business environments where markets shift rapidly, technologies proliferate unceasingly, thus making business life cycles ever shorter. The distinctive characteristics of convergent products, vis-à-vis other types of products, stem from functionality. The functionality has been considered to be the most crucial design basis, directly influencing the product cost, customer satisfaction, and companies' differentiation strategies $[1,4]$. In this respect, although the analysis of CPCs has subsequently been extended to various perspectives on functionality so as to provide design implications, 3 a lacuna still remains in the literature as to systematic design of CPCs based on functionality. In particular, a trade-off that exists in functionality is an urgent issue that should be dealt with because many functions of CPCs may increase the possibility of meeting the customer needs, but at the same time could cause some problems such as increase of cost and complexity [5]. It has been noted that methodological implications have rarely been discussed despite its importance to the overall process. Most firms have also been observed to use informal procedures and qualitative methods which primarily hinge on human intuition and individual experience. Such methods (e.g. brainstorming and intuitive thinking) could be useful for gaining insights, but have become extremely time-consuming and labor-intensive as the complexity of convergent products mounts. Hence, researchers and industrial practitioners need the support of productive and well-organized information that can reduce uncertainty and risk in the concept design stage, and serves as a base for competence development [6].

More recently Relich and Bzdyra [7] proposed a model of measuring the NPD project success that includes indicators such as duration, product development cost and net profit from a product. The proposed methodology is based on identification of the relationships between product success and project environment parameters with the use of artificial neural networks and fuzzy neural system that is compared with the results from linear model. Also Ramezani and Lu [8] proposed a fuzzy method. They developed a fuzzy multiple attribute-based group decision-support system (FMAGDSS) to evaluate projects' performance. The proposed FMAGDSS deals with choosing the most appropriate fuzzy ranking algorithm for solving a given fuzzy multi attribute decision making (FMADM) problem with

${ }^{*}$ Corresponding author: Ermia Aghasi, Faculty of Management, University of Tehran, Iran, Tel: +852.09113152077; E-mail: ermia.aghasi@gmail.com

Received August 03, 2017; Accepted August 24, 2017; Published August 30 2017

Citation: Aghasi E, Momeni M, Hoseini MAS (2017) Integrated Fuzzy PROMETHEE and Fuzzy Linear Program for Functions Evaluation in Convergent Products: Case for Digital Products. Ind Eng Manage 6: 219. doi:10.4172/2169-0316.1000219

Copyright: ( 2017 Aghasi E, et al. This is an open-access article distributed under the terms of the Creative Commons Attribution License, which permits unrestricted use, distribution, and reproduction in any medium, provided the original author and source are credited. 
both qualitative and quantitative criteria (attributes), and uncertain judgments of decision makers [9].

Filippo Emanuele Ciarapica et al. [10] highlighted that traditional methods for evaluating NPD project, focused on the net present value method and real options analysis, lack the flexibility required to model asymmetric multistage decisions and flexible uncertain states. They integrated scenario planning and decision tree analysis for NPD evaluation. Through such integration, scenarios for modeling uncertainties can be generated systematically.

Verworn et al. [11] examined the fuzzy front end of 497 NPD projects in Japanese manufacturing firms, with the results of the empirical analysis suggesting that an early reduction of market and technical uncertainty as well as initial planning prior to development have positive impacts on new product development project success.

The literature reviewed above highlights that authors took into consideration several critical success factors for analyzing NPD success. Because the study carried out here uses the specific case study of a multinational corporation, the literature is organised next against the CSFs relevant to that case.

In this paper, we propose a methodology for functions selection and ranking for convergent products under uncertainty. An integrated decision making mathematical formulation under fuzzy environment is proposed.

The remainder of our work is organized as follows. Next, we develop the problem and its modelling. In Section 3, methods and materials are introduced. In Section 4, a case study is conducted to show the implementation of the methodology. We conclude in Section 5.

\section{Proposed Problem and Model}

Convergent product $(\mathrm{CP})$ is a specific process in new product development (NPD) in which product design (PD) is a significant part.

The aim of CP is to acquire indices or functions to be collected through customer relationship management (CRM) and then should be purified and updated. Traditionally, quality function deployment (QFD) is performed instead of CP. But the limitation of QFD is mainly its focus on quality merely while a group of other indices can be effective such as customers' views of balanced score card (BSC) indices. Thus, in this research a CP based process is proposed to overcome common drawbacks of past methods and provide integrated decision making mechanism for top management.

To do that a two stage process is designed as follows:

1. An environment is proposed to collect customers' views and integrate it with purification and product functions update. The aim here is to identify the indices and present products with alternative function to satisfy customers' utility.

2. Evaluation of functions and indices of products, which was performed using statistical or data mining techniques in the previous literature, is aimed here to include uncertainty of customers' views and will be modelled by a fuzzy set theory decision making method.

Acquiring customers' views on product functions is performed using internet based questionnaire to assess customer satisfaction measure. Then, using a fuzzy PROMETHEE technique, due to uncertainty of data, evaluation of relative significance is performed. Considering a threshold value, purification is done to identify the functions with the highest customers' utility and the most capability of support by producers. After identifying the effective functions, then with respect to the problem objectives an optimization model is performed to provide optimal outputs optimizing the proposed objectives. The objectives are profit, investment expenditures, customer delivery, etc that are transformed to crisp values using fuzzy Analytic hierarchy process (AHP) to better decision making and obtain exact values of the problem.

After performing fuzzy PROMETHEE to evaluate function of products and with respect to qualitative indices of decision making from customers, a tree including weighted functions is obtained. The objective in this proposed tree is finding a set of functions and sub-functions that optimize the objectives of the problem such as maximizing the expected profit, maximizing the customer utility and minimizing the cost. This way and regarding the uncertainty of the problem a modified branching process is designed to solve the problem. The aim here is to develop a modified branching process to obtain a set of functions and sub-functions with respect to the objectives of the problem.

\section{Methods and Materials}

The use of AHP/ANP with fuzzy set theory is widely accepted for dealing with qualitative evaluation attributes. Chen et al. [12] used the fuzzy Technique for Order of Preference by Similarity to Ideal Solution (TOPSIS) method for supplier selection problem. In this study, the F-PROMETHEE technique is preferred because of the fuzzy nature of the supplier selection decision problem [13].

PROMETHEE is the abbreviation of Preference Ranking Organization Method for Enrichment Evaluations, which is an outranking method that initial references are prepared by Brans et al. $[14,15]$ Brans et al. and Vincle [16]. In PROMETHEE method, different preference functions can be defined for criteria Dagdeviren [17]. It is a ranking method which is quite simple in conception and application compared to other methods for MCDM. It is well adapted to the problems where a finite set of alternatives are to be ranked according to several, sometimes conflicting [18-20].

Ulengin et al. [21] listed the advantages of PROMETHEE as follows:

1. PROMETHEE is a user friendly outranking method,

2. It has been successfully applied to real life planning problems

3. Both PROMETHEE I and PROMETHEE II allow both partial and total ranking of the alternatives while still satisfying simplicity.

The evaluation is the starting point of PROMETHEE method. In this phase, alternatives are evaluated with respect to different criteria. These evaluations involve essentially numerical data. Macharis et al. [22] stated that the implementation of PROMETHEE requires two additional types of information, which are as follows:

- Information on the relative importance (i.e. the weights) of the criteria considered,

- Information on the decision-makers' preference function, which he/she uses when comparing the contribution of the alternatives in terms of each separate criterion.

In the literature, there are a few studies with respect to the fuzzy PROMETHEE (F-PROMETHEE) approach. Goumas and Lygerou, Geldermann et al. [23] Chou et al. [24], Tuzkaya, Ozgen et al. [25] have used F-PROMETHEE previously. In the F-PROMETHEE, the main problem arises in comparing two fuzzy numbers and the index, which 
corresponds to a weighted average of the fuzzy numbers, is found a useful way to compare fuzzy numbers. It is determined by the center of weight of the surface representing its membership function [26].

In this problem of convergent product evaluation under uncertainty, first we form the decision matrix using fuzzy PROMETHE, as will be described later. All functions and sub-functions are compared using some specified attributes. Then, using fuzzy linear programming approach the matrices are weighed. Finally, using the obtained weights the functions and sub-functions of convergent products are ranked. A summary of the research process is shown in Figure 1.

Here, we develop a new method to evaluate convergent products in a problem of functions selection under uncertainty. Now, consider two fuzzy numbers below:

$$
\begin{aligned}
& \tilde{A}=\left(a_{1}, a_{2}, a_{3}\right) \\
& \tilde{B}=\left(b_{1}, b_{2}, b_{3}\right) \\
& \tilde{P}_{A B}=\left(P L_{A B}, P m_{A B}, P u_{A B}\right) .
\end{aligned}
$$

Then $\mathrm{P}$ is the weight for comparing two fuzzy numbers. Like a triangular membership function, we have,

$$
\begin{aligned}
& \mathrm{PL}_{\mathrm{AB}}=\left\{\begin{array}{cc}
0 & \frac{a_{1}+a_{2}+a_{3}}{3} \leq \frac{b_{1}+b_{2}+b_{3}}{3} \\
a_{1}-b_{3} & \text { otherwise }
\end{array}\right. \\
& \mathrm{PM}_{\mathrm{AB}}=\left\{\begin{array}{cc}
0 & \frac{a_{1}+a_{2}+a_{3}}{3} \leq \frac{b_{1}+b_{2}+b_{3}}{3} \\
a_{2}-b_{2} & \text { otherwise }
\end{array}\right. \\
& \mathrm{PU}_{\mathrm{AB}}=\left\{\begin{array}{cc}
0 & \frac{a_{1}+a_{2}+a_{3}}{3} \leq \frac{b_{1}+b_{2}+b_{3}}{3} \\
a_{3}-b_{1} & \text { otherwise }
\end{array}\right.
\end{aligned}
$$

The steps of the proposed fuzzy PROMETHEE algorithm are given below.

Collecting convergent product evaluation attributes

\section{Effective attributes selection}

\section{Analyzing functions based on the attributes}

\section{Ranking by FPROMETHEE}

\section{Weighing by FLPP}

\section{Deffuzification by FAHP}

Figure 1: Research process.

\section{Fuzzy PROMETHEE algorithm}

For each attribute a pairwise comparison matrix is in hand.

Step 1: Decision Matrix

\begin{tabular}{|l|l|l|l|l|}
\hline $\mathrm{DM}$ & $\mathbf{C}_{\mathbf{1}}$ & $\mathbf{C}_{\mathbf{1}}$ & $\cdots$ & $\mathbf{C}_{\mathbf{n}}$ \\
\hline $\mathbf{A}_{\mathbf{1}}$ & $\widetilde{\mathrm{x}_{12}}$ & $\widetilde{\mathrm{x}_{12}}$ & $\cdots$ & $\widetilde{\mathrm{x}_{1 \mathrm{n}}}$ \\
\hline $\mathbf{A}_{2}$ & $\widetilde{\mathrm{x}_{21}}$ & $\widetilde{\mathrm{x}_{22}}$ & $\cdots$ & $\widetilde{\mathrm{x}_{2 \mathrm{n}}}$ \\
\hline$\cdot$ & $\cdot$ & $\cdot$ & $\cdots$ & $\cdot$ \\
\hline $\mathbf{A}_{\mathbf{x}}$ & $\cdot$ & $\cdot$ & $\cdots$ & $\cdot$ \\
\hline $\mathbf{W}_{\mathbf{j}}$ & $\widetilde{\mathrm{x}_{\mathrm{m} 1}}$ & $\widetilde{\mathrm{x}_{\mathrm{m} 2}}$ & $\cdots$ & $\widetilde{\mathrm{x}_{\mathrm{mn}}}$ \\
\hline
\end{tabular}

$\widetilde{\mathrm{x}_{\mathrm{ij}}}=\left(\mathrm{l}_{\mathrm{ij}}, \mathrm{M}_{\mathrm{ij}}, \mathrm{U}_{\mathrm{ij}}\right)$

Step 2: pairwise matrix

For any criterion the costs are compared.

\begin{tabular}{|l|l|l|l|l|}
\hline $\mathbf{C}_{1}$ & $\mathbf{A}_{1}$ & $\mathbf{A}_{2}$ & $\cdots$ & $\mathbf{A}_{\mathrm{m}}$ \\
\hline $\mathbf{A}_{1}$ & $\widetilde{\mathrm{p}_{11}^{c_{1}}}$ & $\widetilde{\mathrm{p}_{12}^{c_{1}}}$ & $\cdots$ & $\widetilde{\mathrm{p}_{1 \mathrm{~m}}^{\mathrm{c}_{1}}}$ \\
\hline $\mathbf{A}_{2}$ & & & & \\
\hline$\cdot$ & & & & \\
\hline $\mathbf{P}_{\mathbf{m}}$ & $\widetilde{\mathrm{p}_{\mathrm{m}_{1}}^{\mathrm{c}_{1}}}$ & $\widetilde{\mathrm{p}_{\mathrm{m}_{2}}^{\mathrm{c}_{1}}}$ & $\cdots$ & $\widetilde{\mathrm{p}_{\mathrm{m}_{\mathrm{n}}}^{\mathrm{c}_{1}}}$ \\
\hline
\end{tabular}

$\widetilde{p_{i j}^{c_{k}}}=\left(\widetilde{\mathrm{PL}_{\mathrm{ij}}^{c_{k}}}, \widetilde{\mathrm{PM}_{\mathrm{ij}}^{c_{k}}}, \widetilde{\mathrm{PU}_{\mathrm{ij}}^{c_{k}}}\right)$

$\mathrm{m}: 1, \ldots, \mathrm{j}$

$\mathrm{n}: 1, \ldots, \mathrm{k}$

Step3: preference matrix

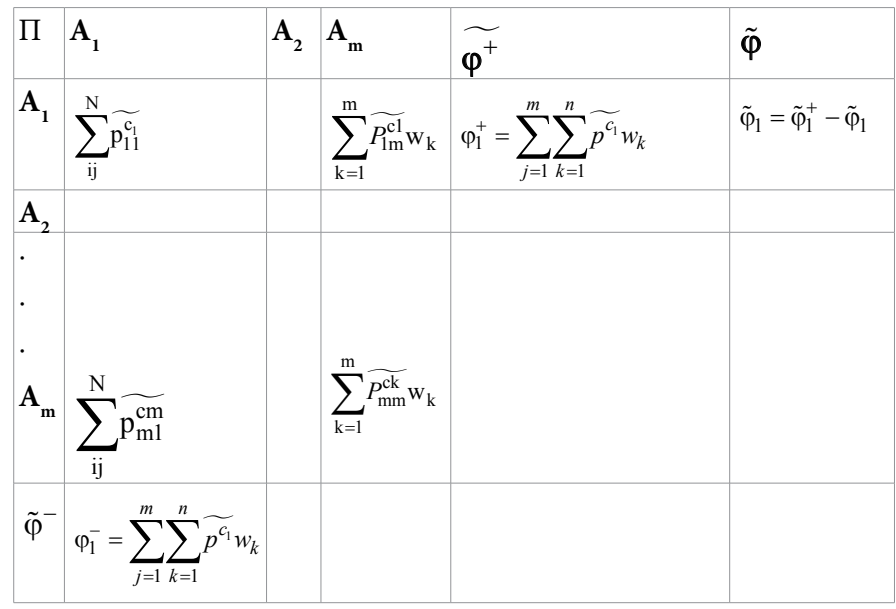

\section{Fuzzy linear program}

A fully fuzzy linear programming problem is used after fuzzy PROMETHEE. We make use of a special ranking function that is used 
in functions evaluation. The uncertainty is modeled with the help of fuzzy triangular numbers. A fully fuzzy linear programming problem can be written as,

$$
\operatorname{Max} / \operatorname{Min} \tilde{z}=\tilde{c}^{t} \cdot \tilde{x}
$$

s.t.

$\tilde{A} \tilde{x} \leq \tilde{b}$

$\tilde{x} \geq 0$

Where $\tilde{z}, \tilde{c}^{t}=\left(\tilde{c}_{1}, \ldots, \tilde{c}_{n}\right), \tilde{x}=\left(\tilde{x}_{1}, \ldots, \tilde{x}_{n}\right), \tilde{A}=\left[\tilde{a}_{i j}\right]_{m \times n}, \tilde{b}=\left(\tilde{b}_{1}, \ldots, \tilde{b}_{m}\right)^{t}$, denote the triangular fuzzy numbers for objective function, fuzzy objective function coefficients, fuzzy technical coefficients and fuzzy resource constraints of the linear programming.

At the end the ranks are fuzzy and should be transformed to crisp for suitable decision making. This way we make use of fuzzy AHP. The priority degree and the dignity degree are in the same scale. So, to obtain $\sum \tilde{\mathrm{p}}_{\mathrm{ij}}^{\mathrm{c}_{\mathrm{k}}}$ the logic used in fuzzy AHP can be employed. But, the problem in FAHP is that the problem becomes crisp from the beginning which is not correct since fuzzy problem should be fuzzy till the final results are in hand.

\section{Case Study}

In this section a case study in an online shopping company is worked out. Three digital products of TV, air conditioner, and refrigerator are considered. These products can be considered as convergent product by adding or removing functions. The attributes to evaluate the functions are,

Price,

Product quality,

On time delivery,

Service quality,

Brand,

and the functions are:
Energy saving mode,

Bluetooth,

Smart control via internet,

Internal memory,

Power, and

Consumption.

The sample understudy is 150 customers' views (which their mean values are employed) and the decision matrix is completed by the experts in sale and customer relationship management departments. As previously explained, first the fuzzy decision matrix is formed and using fuzzy PROMETHEE the pairwise comparison is performed. Then, by FFLP the weights of the attributes pairwise matrices are obtained. Finally, the fuzzy output is transformed to crisp one employing fuzzy analytic hierarchy process. Note that the following computations are for TV and the same process is repeated for the other two products.

The decision matrix is shown in Table 1.

The attributes pairwise comparison is shown in Tables 2-6.

The resulted function/attribute matrix is shown in Table 7.

The fuzzy linear program to obtain the weights is given below:

$$
\begin{aligned}
& \operatorname{Min} Z=(1-\lambda)^{2} M \sum_{j} \sum_{i} y_{i j}^{2}+z_{i j}^{2} \\
& \text { s.t. } \\
& x_{i}-x_{j}-\lambda\left(\ln \frac{m_{i j}}{l_{i j}}\right)+y_{i j} \geq 0, \\
& w_{i}=\frac{\operatorname{Exp}\left(x_{i}\right)}{\sum_{i} x_{i}}, \\
& x_{i}, y_{i j}, z_{i j}, \lambda \geq 0 .
\end{aligned}
$$

\begin{tabular}{|c|c|c|c|c|c|c|c|c|c|c|c|c|c|c|c|}
\hline & \multicolumn{3}{|c|}{ Price } & \multicolumn{3}{|c|}{ Product quality } & \multicolumn{3}{|c|}{ On time delivery } & \multicolumn{3}{|c|}{ Service quality } & \multicolumn{3}{|c|}{ Brand } \\
\hline $\begin{array}{l}\text { Energy saving } \\
\text { mode }\end{array}$ & 0.55 & 0.72 & 0.90 & 0.60 & 0.44 & 0.60 & 0.76 & 0.47 & 0.63 & 0.37 & 0.59 & 0.74 & 0.54 & 0.70 & 0.83 \\
\hline Bluetooth & 0.27 & 0.40 & 0.57 & 0.42 & 0.60 & 0.69 & 0.07 & 0.22 & 0.38 & 0.32 & 0.59 & 0.71 & 0.44 & 0.62 & 0.79 \\
\hline $\begin{array}{c}\text { Smart control via } \\
\text { internet }\end{array}$ & 0.71 & 0.83 & 1.00 & 0.93 & 0.98 & 0.99 & 0.66 & 0.81 & 1.00 & 0.48 & 0.65 & 0.80 & 0.63 & 0.76 & 0.86 \\
\hline Internal memory & 0.70 & 0.82 & 0.90 & 0.88 & 0.91 & 0.94 & 0.85 & 0.94 & 0.99 & 0.52 & 0.70 & 0.83 & 0.30 & 0.45 & 0.62 \\
\hline Power & 0.50 & 0.65 & 0.80 & 0.64 & 0.82 & 0.90 & 0.87 & 0.91 & 0.97 & 0.53 & 0.71 & 0.79 & 0.29 & 0.41 & 0.54 \\
\hline Consumption & 0.63 & 0.81 & 0.91 & 0.24 & 0.39 & 0.59 & 0.66 & 0.79 & 0.97 & 0.37 & 0.63 & 0.76 & 0.43 & 0.54 & 0.64 \\
\hline Wight & 0.21 & 0.39 & 0.54 & 0.56 & 0.67 & 0.77 & 0.74 & 0.86 & 0.93 & 0.47 & 0.67 & 0.80 & 0.77 & 0.84 & 0.90 \\
\hline
\end{tabular}

\begin{tabular}{|c|c|c|c|c|c|c|c|c|c|c|c|c|c|c|c|c|c|c|}
\hline \multirow{2}{*}{\begin{tabular}{|c|} 
Price \\
$\begin{array}{c}\text { Energy saving } \\
\text { mode }\end{array}$ \\
\end{tabular}} & \multicolumn{3}{|c|}{ Energy saving mode } & \multicolumn{3}{|c|}{ Bluetooth } & \multicolumn{3}{|c|}{$\begin{array}{c}\text { Smart control via } \\
\text { internet }\end{array}$} & \multicolumn{3}{|c|}{ Internal memory } & \multicolumn{3}{|c|}{ Power } & \multicolumn{3}{|c|}{ Consumption } \\
\hline & 0.00 & 0.00 & 0.00 & -0.02 & 0.32 & 0.64 & 0.00 & 0.00 & 0.00 & 0.00 & 0.00 & 0.00 & -0.25 & 0.07 & 0.40 & -0.25 & 0.00 & 0.00 \\
\hline Bluetooth & 0.00 & 0.00 & 0.00 & 0.00 & 0.00 & 0.00 & 0.00 & 0.00 & 0.00 & 0.00 & 0.00 & 0.00 & 0.00 & 0.00 & 0.00 & 0.00 & 0.00 & 0.00 \\
\hline $\begin{array}{l}\text { Smart control } \\
\text { via internet }\end{array}$ & -0.19 & 0.12 & 0.45 & 0.14 & 0.44 & 0.73 & 0.00 & 0.00 & 0.00 & -0.19 & 0.02 & 0.30 & -0.09 & 0.18 & 0.50 & -0.09 & 0.02 & 0.37 \\
\hline Internal memory & -0.20 & 0.10 & 0.35 & 0.13 & 0.42 & 0.64 & 0.00 & 0.00 & 0.00 & 0.00 & 0.00 & 0.00 & -0.10 & 0.17 & 0.40 & -0.10 & 0.01 & 0.28 \\
\hline Power & 0.00 & 0.00 & 0.00 & -0.07 & 0.25 & 0.53 & 0.00 & 0.00 & 0.00 & 0.00 & 0.00 & 0.00 & 0.00 & 0.00 & 0.00 & 0.00 & 0.00 & 0.00 \\
\hline Consumption & -0.28 & 0.09 & 0.35 & 0.06 & 0.41 & 0.64 & 0.00 & 0.00 & 0.00 & 0.00 & 0.00 & 0.00 & -0.17 & 0.16 & 0.41 & 0.00 & 0.00 & 0.00 \\
\hline
\end{tabular}

Where $\mathrm{M}$ is a large number and the aim of the linear model is to find the weights.

Table 1: The decision matrix.

Table 2: Pairwise comparison for price attribute. 
Citation: Aghasi E, Momeni M, Hoseini MAS (2017) Integrated Fuzzy PROMETHEE and Fuzzy Linear Program for Functions Evaluation in Convergent Products: Case for Digital Products. Ind Eng Manage 6: 219. doi:10.4172/2169-0316.1000219

Page 5 of 6

\begin{tabular}{|c|c|c|c|c|c|c|c|c|c|c|c|c|c|c|c|c|c|c|}
\hline \multirow{2}{*}{\begin{tabular}{|c|} 
Product quality \\
$\begin{array}{c}\text { Energy saving } \\
\text { mode }\end{array}$ \\
\end{tabular}} & \multicolumn{3}{|c|}{ Energy saving mode } & \multicolumn{3}{|c|}{ Bluetooth } & \multicolumn{3}{|c|}{$\begin{array}{c}\text { Smart control via } \\
\text { internet }\end{array}$} & \multicolumn{3}{|c|}{ Internal memory } & \multicolumn{3}{|c|}{ Power } & \multicolumn{3}{|c|}{ Consumption } \\
\hline & 0.00 & 0.00 & 0.00 & 0.00 & 0.00 & 0.00 & 0.00 & 0.00 & 0.00 & 0.00 & 0.00 & 0.00 & 0.00 & 0.00 & 0.00 & 0.00 & 0.06 & 0.37 \\
\hline Bluetooth & -0.18 & 0.15 & 0.09 & 0.00 & 0.00 & 0.00 & 0.00 & 0.00 & 0.00 & 0.00 & 0.00 & 0.00 & 0.00 & 0.00 & 0.00 & 0.00 & 0.21 & 0.45 \\
\hline $\begin{array}{l}\text { Smart control } \\
\text { via internet }\end{array}$ & 0.33 & 0.53 & 0.38 & 0.24 & 0.38 & 0.56 & 0.00 & 0.00 & 0.00 & -0.01 & 0.00 & 0.11 & 0.03 & 0.16 & 0.35 & 0.03 & 0.59 & 0.75 \\
\hline Internal memory & 0.28 & 0.47 & 0.34 & 0.19 & 0.32 & 0.52 & 0.00 & 0.00 & 0.00 & 0.00 & 0.00 & 0.00 & -0.02 & 0.09 & 0.30 & -0.02 & 0.53 & 0.70 \\
\hline Power & 0.04 & 0.38 & 0.29 & -0.05 & 0.22 & 0.47 & 0.00 & 0.00 & 0.00 & 0.00 & 0.00 & 0.00 & 0.00 & 0.00 & 0.00 & 0.00 & 0.43 & 0.66 \\
\hline Consumption & 0.00 & 0.00 & 0.00 & 0.00 & 0.00 & 0.00 & 0.00 & 0.00 & 0.00 & 0.00 & 0.00 & 0.00 & 0.00 & 0.00 & 0.00 & 0.00 & 0.00 & 0.00 \\
\hline
\end{tabular}

Table 3: Pairwise comparison for product quality.

\begin{tabular}{|c|c|c|c|c|c|c|c|c|c|c|c|c|c|c|c|c|c|c|}
\hline \multirow{2}{*}{$\begin{array}{l}\text { On time delivery } \\
\text { Energy saving mode }\end{array}$} & \multicolumn{3}{|c|}{ Energy saving mode } & \multicolumn{3}{|c|}{ Bluetooth } & \multicolumn{3}{|c|}{$\begin{array}{c}\text { Smart control via } \\
\text { internet }\end{array}$} & \multicolumn{3}{|c|}{ Internal memory } & \multicolumn{3}{|c|}{ Power } & \multicolumn{3}{|c|}{ Consumption } \\
\hline & 0.0 & 0.0 & 0.0 & 0.4 & 0.2 & 0.6 & 0.0 & 0.0 & 0.0 & 0.0 & 0.0 & 0.0 & 0.0 & 0.0 & 0.0 & 0.0 & 0.0 & 0.0 \\
\hline Bluetooth & 0.0 & 0.0 & 0.0 & 0.0 & 0.0 & 0.0 & 0.0 & 0.0 & 0.0 & 0.0 & 0.0 & 0.0 & 0.0 & 0.0 & 0.0 & 0.0 & 0.0 & 0.0 \\
\hline $\begin{array}{c}\text { Smart control via } \\
\text { internet }\end{array}$ & 0.0 & 0.3 & 0.2 & 0.3 & 0.6 & 0.9 & 0.0 & 0.0 & 0.0 & 0.0 & 0.0 & 0.0 & 0.0 & 0.0 & 0.0 & 0.0 & 0.0 & 0.3 \\
\hline Internal memory & 0.2 & 0.5 & 0.2 & 0.5 & 0.7 & 0.9 & -0.2 & 0.1 & 0.3 & 0.0 & 0.0 & 0.0 & -0.1 & 0.0 & 0.1 & -0.1 & 0.1 & 0.3 \\
\hline Power & 0.2 & 0.4 & 0.2 & 0.5 & 0.7 & 0.9 & -0.1 & 0.1 & 0.3 & 0.0 & 0.0 & 0.0 & 0.0 & 0.0 & 0.0 & 0.0 & 0.1 & 0.3 \\
\hline Consumption & 0.0 & 0.3 & 0.2 & 0.3 & 0.6 & 0.9 & 0.0 & 0.0 & 0.0 & 0.0 & 0.0 & 0.0 & 0.0 & 0.0 & 0.0 & 0.0 & 0.0 & 0.0 \\
\hline
\end{tabular}

Table 4: Pairwise comparison for on time delivery.

\begin{tabular}{|c|c|c|c|c|c|c|c|c|c|c|c|c|c|c|c|c|c|c|}
\hline \multirow{2}{*}{$\begin{array}{c}\text { Service quality } \\
\text { Energy saving } \\
\text { mode }\end{array}$} & \multicolumn{3}{|c|}{ Energy saving mode } & \multicolumn{3}{|c|}{ Bluetooth } & \multicolumn{3}{|c|}{$\begin{array}{c}\text { Smart control via } \\
\text { internet }\end{array}$} & \multicolumn{3}{|c|}{ Internal memory } & \multicolumn{3}{|c|}{ Power } & \multicolumn{3}{|c|}{ Consumption } \\
\hline & 0.00 & 0.00 & 0.00 & -0.34 & 0.00 & 0.41 & 0.00 & 0.00 & 0.00 & 0.00 & 0.00 & 0.00 & 0.00 & 0.00 & 0.00 & 0.00 & 0.00 & 0.00 \\
\hline Bluetooth & 0.00 & 0.00 & 0.00 & 0.00 & 0.00 & 0.00 & 0.00 & 0.00 & 0.00 & 0.00 & 0.00 & 0.00 & 0.00 & 0.00 & 0.00 & 0.00 & 0.00 & 0.00 \\
\hline $\begin{array}{l}\text { Smart control } \\
\text { via internet }\end{array}$ & -0.26 & 0.06 & 0.43 & -0.23 & 0.06 & 0.48 & 0.00 & 0.00 & 0.00 & 0.00 & 0.00 & 0.00 & 0.00 & 0.00 & 0.00 & 0.00 & 0.02 & 0.43 \\
\hline Internal memory & -0.22 & 0.11 & 0.47 & -0.19 & 0.11 & 0.51 & -0.28 & 0.05 & 0.35 & 0.00 & 0.00 & 0.00 & -0.27 & -0.01 & 0.30 & -0.27 & 0.07 & 0.46 \\
\hline Power & -0.21 & 0.12 & 0.43 & -0.18 & 0.12 & 0.47 & -0.27 & 0.06 & 0.31 & 0.00 & 0.00 & 0.00 & 0.00 & 0.00 & 0.00 & 0.00 & 0.08 & 0.42 \\
\hline Consumption & -0.37 & 0.04 & 0.39 & -0.34 & 0.04 & 0.43 & 0.00 & 0.00 & 0.00 & 0.00 & 0.00 & 0.00 & 0.00 & 0.00 & 0.00 & 0.00 & 0.00 & 0.00 \\
\hline
\end{tabular}

Table 5: Pairwise comparison for service quality.

\begin{tabular}{|c|c|c|c|c|c|c|c|c|c|c|c|c|c|c|c|c|c|c|}
\hline \multirow{2}{*}{\begin{tabular}{|c|} 
Brand \\
$\begin{array}{c}\text { Energy saving } \\
\text { mode }\end{array}$
\end{tabular}} & \multicolumn{3}{|c|}{ Energy saving mode } & \multicolumn{3}{|c|}{ Bluetooth } & \multicolumn{3}{|c|}{$\begin{array}{c}\text { Smart control via } \\
\text { internet }\end{array}$} & \multicolumn{3}{|c|}{ Internal memory } & \multicolumn{3}{|c|}{ Power } & \multicolumn{3}{|c|}{ Consumption } \\
\hline & 0.00 & 0.00 & 0.00 & -0.25 & 0.07 & 0.38 & 0.00 & 0.00 & 0.00 & -0.08 & 0.24 & 0.53 & 0.00 & 0.29 & 0.53 & 0.00 & 0.16 & 0.40 \\
\hline Bluetooth & 0.00 & 0.00 & 0.00 & 0.00 & 0.00 & 0.00 & 0.00 & 0.00 & 0.00 & -0.17 & 0.17 & 0.49 & -0.09 & 0.22 & 0.50 & -0.09 & 0.09 & 0.36 \\
\hline $\begin{array}{l}\text { Smart control } \\
\text { via internet }\end{array}$ & -0.20 & 0.06 & 0.32 & -0.17 & 0.13 & 0.42 & 0.00 & 0.00 & 0.00 & 0.01 & 0.31 & 0.56 & 0.09 & 0.35 & 0.57 & 0.09 & 0.22 & 0.43 \\
\hline Internal memory & 0.00 & 0.00 & 0.00 & 0.00 & 0.00 & 0.00 & 0.00 & 0.00 & 0.00 & 0.00 & 0.00 & 0.00 & -0.24 & 0.05 & 0.32 & -0.24 & 0.00 & 0.00 \\
\hline Power & 0.00 & 0.00 & 0.00 & 0.00 & 0.00 & 0.00 & 0.00 & 0.00 & 0.00 & 0.00 & 0.00 & 0.00 & 0.00 & 0.00 & 0.00 & 0.00 & 0.00 & 0.00 \\
\hline Consumption & 0.00 & 0.00 & 0.00 & 0.00 & 0.00 & 0.00 & 0.00 & 0.00 & 0.00 & -0.19 & 0.08 & 0.34 & -0.11 & 0.13 & 0.34 & 0.00 & 0.00 & 0.00 \\
\hline
\end{tabular}

Table 6: Pairwise comparison for brand.

\begin{tabular}{|c|c|c|c|c|c|c|c|c|c|c|c|c|c|c|c|c|c|c|}
\hline \multirow{2}{*}{\begin{tabular}{|c|} 
Brand \\
$\begin{array}{c}\text { Energy saving } \\
\text { mode }\end{array}$ \\
\end{tabular}} & \multicolumn{3}{|c|}{ Energy saving mode } & \multicolumn{3}{|c|}{ Bluetooth } & \multicolumn{3}{|c|}{$\begin{array}{c}\text { Smart control via } \\
\text { internet }\end{array}$} & \multicolumn{3}{|c|}{ Internal memory } & \multicolumn{3}{|c|}{ Power } & \multicolumn{3}{|c|}{ Consumption } \\
\hline & 0.00 & 0.00 & 0.00 & -0.08 & 0.40 & 1.54 & 0.00 & 0.00 & 0.00 & -0.06 & 0.21 & 0.48 & -0.05 & 0.27 & 0.70 & -0.05 & 0.18 & 0.64 \\
\hline Bluetooth & -0.10 & 0.10 & 0.07 & 0.00 & 0.00 & 0.00 & 0.00 & 0.00 & 0.00 & -0.13 & 0.14 & 0.45 & -0.07 & 0.18 & 0.45 & -0.07 & 0.22 & 0.68 \\
\hline $\begin{array}{l}\text { Smart control } \\
\text { via internet }\end{array}$ & -0.10 & 0.79 & 1.40 & 0.13 & 1.09 & 2.45 & 0.00 & 0.00 & 0.00 & -0.04 & 0.26 & 0.75 & 0.07 & 0.47 & 1.05 & 0.07 & 0.63 & 1.82 \\
\hline Internal memory & 0.18 & 0.83 & 1.03 & 0.39 & 1.07 & 2.00 & -0.24 & 0.14 & 0.58 & 0.00 & 0.00 & 0.00 & -0.43 & 0.18 & 1.10 & -0.43 & 0.53 & 1.36 \\
\hline Power & 0.10 & 0.71 & 0.76 & 0.23 & 0.92 & 1.86 & -0.22 & 0.12 & 0.53 & 0.00 & 0.00 & 0.00 & 0.00 & 0.00 & 0.00 & 0.00 & 0.45 & 1.13 \\
\hline Consumption & -0.20 & 0.34 & 0.70 & 0.06 & 0.68 & 1.53 & 0.00 & 0.00 & 0.00 & -0.14 & 0.07 & 0.31 & -0.12 & 0.17 & 0.53 & 0.00 & 0.00 & 0.00 \\
\hline
\end{tabular}

Table 7: Function/function matrix.

Solving the model in lingo optimization software we have:

Local optimal solution found.

Objective value: $0.1232595 \mathrm{E}-27$

Infeasibilities: 0.3178013E-14
Total solver iterations: 41

And finally, the crisp values and the full ranking of functions is:

The weights are obtained to be: $0.21,0.14,0.175,0.12,0.175$, and 0.18 for the functions, respectively. 
Citation: Aghasi E, Momeni M, Hoseini MAS (2017) Integrated Fuzzy PROMETHEE and Fuzzy Linear Program for Functions Evaluation in Convergent Products: Case for Digital Products. Ind Eng Manage 6: 219. doi:10.4172/2169-0316.1000219

Thus, with respect to the attributes and the views of the customers the importance weights of the functions show that energy saving mode ranks first and then consumption is in the second place. Smart control via internet and power are commonly in the third place. Internal memory is the last function customers considered as buying criteria.

\section{Conclusions}

In this work a new integration between PROMETHEE and linear programming in fuzzy environment was proposed. The decision making problem is of convergent product. First the fuzzy decision matrix was formed and using fuzzy PROMETHEE the pairwise comparison was performed. Then, by fuzzy linear programming the weights of the functions and attributes pairwise matrices were obtained. Finally, the fuzzy output was transformed to crisp one employing fuzzy analytic hierarchy process. The applicability and the validity of the proposed method were tested in a case study.

\section{References}

1. Greenstein S, Khanna T (1997) What does industry convergence mean? In Yoffie DB (ed.) Competing in the age of digital convergence. Boston: Harvard Business School Press, pp: 201-226.

2. Gill T (2008) Convergent products: What functionalities add more value to the base? Journal of Marketing 72: 46-62.

3. Gill T, Lei J (2009) Convergence in the high-technology consumer markets: Not all brands gain equally from adding new functionalities to products. Marketing Letters 20: 91-103.

4. Kaluza B, Blecker T, Bischof C (1999) Implications of digital convergence on strategic management. In: Dahiya SB (ed.) The current state of economic science. Rohtak: Spellbound Publications, pp: 2223-2249.

5. Rust RT, Thompson DV, Hamilton RW (2006) Defeating feature fatigue Harvard Business Review 84: 37-47.

6. Moradinaftchali V, Song L, Wang X (2016) Improvement in quality and productivity of an assembled product: A riskless approach. Computers \& Industrial Engineering 94: 74-82.

7. Relich M, Bzdyra K (2014) Estimating new product success with the use of intelligent systems. Foundations of Management 6: 7-20.

8. Ramezani F, Lu J (2014) An intelligent group decision-support system and its application for project performance evaluation. Journal of Enterprise Information Management 27: 278-291.

9. Chen L, Pan W (2016) BIM-aided variable fuzzy multi-criteria decision making of low-carbon building measures selection. Sustainable Cities and Society 27 222-232.

10. Ciarapica FE, Bevilacqua M, Mazzuto G (2015) Performance analysis of new product development projects: An approach based on value stream mapping. International Journal of Productivity and Performance Management 65: 177206

11. Verworn B, Herstatt, C, Nagahira A (2008) The fuzzy front end of Japanese new product development projects: Impact on success and differences between incremental and radical projects. R\&D Management 38: 1-19.

12. Chen CT, Lin CT, Huang SF (2006) A fuzzy approach for supplier evaluation and selection in supply chain management. Int J Prod Econ 102: 289-301.

13. Kavilal EG, Prasanna Venkatesan S, Harsh Kumar KD (2017) An integrated fuzzy approach for prioritizing supply chain complexity drivers of an Indian mining equipment manufacturer. Resources Policy 51: 204-218.

14. Brans JP, Mareschal B, Vincke P (1984) PROMETHEE: A new family of outranking methods in MCDM. In: Brans JP (ed.) Operational Research IFORS 84. North-Holland, Amsterdam, pp: 477-490.

15. Brans JP, Vincke $P$, Mareschal $B(1986)$ How to select and how to rank projects: the PROMETHEE method. Eur. J. Oper. Res 14: 228-238.

16. Brans JP, Vincle $P$ (1985) A preference ranking organization method. Manage Sci 31: 647-656

17. Dagdeviren M (2008) Decision making in equipment selection: an integrated approach with AHP and PROMETHEE. J Intell Manuf 19: 397-406.

18. Bilsel RU, Buyukozkan G, Ruan D (2006) A fuzzy preference ranking model for a quality evaluation of hospital web sites. In J Intell Syst 21: 1181-1197.

19. Albadvi A, Chaharsooghi SK, Esfahanipour A (2007) Decision making in stock trading: an application of PROMETHEE. Eur J Oper Res 177: 673-683.

20. Tuzkaya G, Gulsun B, Kahraman C, Ozgen D (2010) An integrated fuzzy multicriteria decision making methodology for material handling equipment selection problem and an application. Expert Syst Appl 37: 2853-2863.

21. Ulengin F, Topçu Y, Sahin SO (2001) An Integrated decision aid system for Bosporous watercrossing problem. Eur J Oper Res 134: 179-192.

22. Macharis C, Springael J, de Brucker K, Verbeke A (2004) PROMETHEE and AHP: the design of operational synergies in multicriteria analysis. Stengthening PROMETHEE with ideas of AHP. Eur J Oper Res 153: 307-317.

23. Goumas M, Lygerou V (2000) An extension of the PROMETHEE method for decision making in fuzzy environment: ranking of alternative energy exploitation projects. Eur J Oper Res 123: 606-613.

24. Chou WC, Lin WT, Lin CY (2007) Application of fuzzy theory and PROMETHEE technique to evaluate suitable ecotechnology method: a case study in Shismen reservoir watershed. Taiwan. Ecol. Eng 31: 269-280.

25. Ozgen A, Tuzkaya G, Tuzkaya UR, Ozgen D (2011) A Multi-Criteria Decision Making Approach for Machine Tool Selection Problem in a Fuzzy Environment Int J Comput Intell Syst 4: 431-445.

26. Afful-Dadzie E, Oplatkova ZK, Nabareseh S (2015) Selecting Start-Up Businesses in a Public Venture Capital Financing using Fuzzy PROMETHEE. Procedia Computer Science 60: 63-72. 